\title{
PROGRAM QUR'ANIC ADVENTURE MAHASISWA KKN STIBA MAKASSAR DI KABUPATEN GOWA
}

\section{QUR'ANIC ADVENTURE PROGRAM OF KKN STIBA MAKASSAR STUDENTS IN GOWA REGENCY}

\author{
Hendra Wijaya \\ Sekolah Tinggi Ilmu Islam dan Bahasa Arab (STIBA) Makassar \\ Email: hendrawijaya@stiba.ac.id \\ Rosmita \\ Sekolah Tinggi Ilmu Islam dan Bahasa Arab (STIBA) Makassar \\ Email: rosmt84@gmail.com \\ Istikhariyah Muin \\ Sekolah Tinggi Ilmu Islam dan Bahasa Arab (STIBA) Makassar \\ Email: istikhariyahmuin@stiba.ac.id
}

\begin{tabular}{|c|c|}
\hline Keywords : & ABSTRACT \\
\hline $\begin{array}{l}\text { Gowa Regency, KKN STIBA } \\
\text { Makassar, Qur'anic Adventure, }\end{array}$ & $\begin{array}{l}\text { The Qur'an is a holy book that is a guideline in the implementation } \\
\text { and practice of Islam. Therefore, reading and studying the Qur'an is } \\
\text { an obligation for all Muslims. The purpose of community service } \\
\text { implementation through the Qur'anic Adventure program is intended } \\
\text { to present the activities of fostering the Qur'an in the community, } \\
\text { especially in rural areas, in order to bring the community closer to } \\
\text { the values of the Qur'aniyah as the first step of an intensive Islamic } \\
\text { learning program. Based on the initial observations, the Qur'anic } \\
\text { Adventure program consists of five activities, namely: 1) Halaqoh } \\
\text { Qur'aniyah; 2) Safari Da'wah and Waqf Qur'an; 3) Education of the } \\
\text { Muslim Qur'an (DIROSA); 4) Construction of The Qur'an Education } \\
\text { Park (TPA), and 5) Tahfiz Weekend Muslimah. The results of the } \\
\text { implementation of KKN program packaged in the Qur'anic } \\
\text { Adventure program can increase public insights and raise public } \\
\text { awareness in efforts to improve the spiritual field, especially the } \\
\text { Qur'an. }\end{array}$ \\
\hline \multirow{2}{*}{$\begin{array}{l}\text { Kata kunci : } \\
\text { Kabupaten Gowa, KKN STIBA } \\
\text { Makassar, Qur'anic Adventure, }\end{array}$} & ABSTRAK \\
\hline & $\begin{array}{l}\text { Kabupaten Gowa merupakan salah satu daerah di Sulawesi Selatan } \\
\text { yang terkenal dengan potensi alam dan pariwisata. Kabupaten Gowa } \\
\text { juga dikenal dengan tipologi masyarakat yang religious sehingga } \\
\text { menjadi wilayah yang ramah terhadap berbagai program pembinaan } \\
\text { Islam, tidak terkecuali pembinaan Al-Qur'an. Al-Qur'an merupakan } \\
\text { kitab suci yang menjadi pedoman dalam pelaksanaan dan } \\
\text { pengamalan Islam. Oleh karena itu, membaca dan mempelajari Al- } \\
\text { Qur'an merupakan kewajiban bagi seluruh umat muslim. Tujuan } \\
\text { pelaksanaan pengabdian masyarakat melalui program Qur'anic } \\
\text { Adventure dimaksudkan untuk menghadirkan kegiatan pembinaan } \\
\text { Al-Qur'an di tengah masyarakat, khususnya di daerah pedesaan, agar } \\
\text { dapat lebih mendekatkan masyarakat terhadap nilai-nilai Qur'aniyah }\end{array}$ \\
\hline
\end{tabular}


sebagai langkah awal program pembelajaran Islam secara intensif. Berdasarkan hasil pengamatan awal, maka program Qur'anic Adventure yang dilaksanakan terdiri dari lima kegiatan yaitu: 1) Halaqoh Qur'aniyah; 2) Safari Dakwah dan Wakaf Qur'an; 3) Pendidikan Al-Qur'an Muslimah (DIROSA); 4) Pembinaan Taman Pendidikan Al-Qur'an (TPA), dan 5) Tahfiz Weekend Muslimah. Hasil pelaksanaan Program KKN yang dikemas dalam program Qur'anic Adventure dapat meningkatkan wawasan masyarakat serta menumbuhkan kesadaran masyarakat dalam upaya peningkatan bidang spiritual, khususnya Al-Qur'an.

Diterima: 20 April 2021; Direvisi: 11 Mei 2021; Disetujui: 28 Mei 2021; Tersedia online: 18 Juni 2021

How to cite: Hendra Wijaya, Rosmita, Istikhariyah Muin "Program Qur'anic Adventure Mahasiswa KKN STIBA Makassar di Kabupaten Gowa", WAHATUL MUJTAMA': Jurnal Pengabdian Masyarakat Vol.2, No.1 (Juni 18, 2021): 58-69. doi: https://doi.org/10.36701/wahatul.v2i1.347

\section{PENDAHULUAN}

Kabupaten Gowa adalah salah satu Daerah Tingkat II di Provinsi Sulawesi Selatan, Indonesia. Ibu kota Kabupaten ini terletak di Kota Sungguminasa. Kabupaten ini memiliki luas wilayah $1.883,33 \mathrm{~km}^{2}$ dan berpenduduk sebanyak 772.684 jiwa di tahun 2020. Dalam khasanah sejarah nasional, nama Gowa sudah tidak asing lagi. Mulai abad ke-15, Kerajaan Gowa merupakan kerajaan maritim yang besar pengaruhnya di perairan nusantara. Bahkan, dari kerajaan ini juga muncul nama pahlawan nasional yang bergelar Ayam Jantan dari Timur, Sultan Hasanuddin, Raja Gowa XVI yang berani melawan VOC Belanda pada tahun-tahun awal kolonialisasinya di Indonesia. Kerajaan Gowa memang akhirnya takluk kepada Belanda lewat Perjanjian Bungaya. Namun, sebagai sebuah kerajaan, Gowa tidak lagi berjaya, kerajaan ini mampu memberi warisan terbesarnya, yaitu Pelabuhan Makassar. Pelabuhan yang kemudian berkembang menjadi Kota Makassar ini dapat disebut anak kandungnya, sedangkan Kerajaan Gowa sendiri merupakan cikal bakal Kabupaten Gowa sekarang.

Kota Makassar lebih dikenal khalayak umum dibandingkan dengan Kabupaten Gowa. Padahal secara realitas dan akar sejarah, sampai sekarang Kabupaten Gowa ibaratnya masih menjadi ibu bagi kota. Kabupaten yang hanya berjarak tempuh sekitar 10 menit dari Kota Makassar ini memasok sebagian besar kebutuhan dasar kehidupan kota, mulai dari bahan material untuk pembangunan fisik, bahan pangan, terutama sayur-mayur, sampai aliran air bersih dari Waduk Bili-Bili. Kemampuan Kabupaten Gowa menyuplai kebutuhan bagi daerah sekitarnya dikarenakan keadaan alamnya. Kabupaten seluas 1.883,32 kilometer persegi ini memiliki enam gunung, di mana yang tertinggi adalah Gunung Bawakaraeng. Daerah ini juga dilalui oleh Sungai Jeneberang yang di daerah pertemuannya dengan Sungai Jenelata dibangun Waduk Bili-Bili. Keuntungan alam 
ini menjadikan tanah Gowa kaya akan bahan galian, di samping tanahnya yang subur.

Secara geografis, Kabupaten Gowa terletak pada 5³3' - 5³4' Lintang Selatan dan $120^{\circ} 38^{\prime}-120^{\circ} 33^{\prime}$ Bujur Timur. Luas wilayah Kabupaten Gowa adalah $\pm 1.883,33 \mathrm{~km}^{2}$. Kabupaten Gowa sendiri terdiri dari wilayah dataran rendah dan wilayah dataran tinggi dengan ketinggian anatar 10 - $2800 \mathrm{~m}$ di atas permukaan air laut. Namun, wilayah Kabupaten Gowa sebagian besar merupakan dataran tinggi yaitu sekitar 72,26\% terutama di bagian timur hingga selatan karena merupakan daerah pegunangan Tinggimoncong, Bawakaraeng, Lompobattang, dan pegununggan Batureppe-Cindako. Dengan demikian, dari total luas Kabupaten Gowa, 35,30\% luas daerahnya mempunyai kemiringan tanah di atas 40 derajat, yaitu pada wilayah Kecamatan Parangloe, Tinggimoncong, Bungaya dan Tompobulu.

Wilayah Kabupaten Gowa menurut klasifikasi iklim Koppen beriklim muson tropis (Am) dengan dua musim yang dipengaruhi oleh pergerakan angin muson, yaitu musim penghujan dan musim kemarau. Musim kemarau di wilayah Gowa disebabkan oleh hembusan angin muson timur-tenggara yang bersifat kering dan tidak banyak membawa uap air dan terjadi pada periode Mei hingga Oktober. Sementara itu, musim penghujan di wilayah kabupaten ini diakibatkan oleh hembusan angin muson barat laut-barat daya yang bersifat basah dan lembab. Musim penghujan di wilayah Gowa berlangsung pada periode November hingga April dengan bulan terbasah adalah Januari yang curah hujan bulanannya lebih dari $500 \mathrm{~mm}$ per bulan. Curah hujan tahunan di wilayah Kabupaten Gowa berkisar pada angka 2.000-3.000 mm per tahun dengan jumlah hari hujan berkisar antara 100180 hari hujan per tahun. Suhu udara di wilayah Kabupaten Gowa berkisar pada angka $22^{\circ}-33^{\circ} \mathrm{C}$ dengan tingkat kelembapan nisbi $\pm 81 \%$.

Kabupaten Gowa dilalui oleh banyak sungai yang cukup besar yaitu ada 15 sungai. Sungai dengan luas daerah aliran yang terbesar adalah Sungai Jeneberang yaitu seluas $881 \mathrm{~km}^{2}$ dengan panjang sungai utama $90 \mathrm{~km}$. Adapun batas-batas wilayah Kabupaten Gowa dideskripsikan pada tabel berikut:

\begin{tabular}{cc}
\hline Arah Batas & Wilayah/Daerah Batas \\
\hline Utara & Kota Makassar, Kabupaten Maros dan \\
Kabupaten Bone
\end{tabular}


Potensi Kabupaten Gowa yang sesungguhnya adalah sektor pertanian. Pekerjaan utama penduduk kabupaten yang pada tahun 2000 lalu berpendapatan per kapita Rp. 2,09 juta ini adalah bercocok tanam, dengan sub sektor pertanian tanaman pangan sebagai andalan. Sektor pertanian memberi kontribusi sebesar 45 persen atau senilai Rp. 515,2 miliar. Lahan persawahan yang tidak sampai 20 persen (3,640 hektare) dari total lahan kabupaten mampu memberikan hasil yang memadai. Dari berbagai produksi tanaman pertanian seperti padi dan palawija, tanaman hortikultura menjadi primadona.

Kecamatan-kecamatan yang berada di dataran tinggi seperti Parangloe, Bungaya dan terutama Tinggimoncong merupakan sentra penghasil sayur-mayur. Sayuran yang paling banyak dibudidayakan adalah kentang, kubis, sawi, bawang daun dan buncis. Per-tahunnya hasil panen sayur-sayuran melebihi 5.000 ton. Sayuran dari Kabupaten Gowa mampu memenuhi pasar Kota Makassar dan sekitarnya, bahkan sampai ke Pulau Kalimantan dan Maluku melalui Pelabuhan Parepare dan Pelabuhan Mamuju. Selain bertani sayur yang memiliki masa tanam pendek, petani Gowa juga banyak yang bertani tanaman umur panjang. Salah satunya adalah tanaman markisa (Fassifora sp).

Bahan-bahan galian golongan C di sepanjang Daerah Aliran Sungai (DAS) Jenebarang, seperti pasir, batu kali dan kerikil secara turun-temurun mampu memberikan nafkah bagi penduduk sekitarnya. Kontribusi sektor ini dalam kegiatan ekonomi tahun 2000 nilainya mencapai Rp. 105,4 miliar atau 9,13 persen, tetapi sumbangan sektor ini terhadap kas Pemerintah Kabupaten (Pemkab) cukup signifikan. Pada tahun anggaran 2001, Pemkab menargetkan Rp. 2,03 miliar dari pajak bahan galian golongan $\mathrm{C}$ untuk mengisi Pendapatan Asli Daerah (PAD). Kegiatan penggalian memang cukup besar karena selain tersedianya material dari DAS, juga ada batu gunung dan tanah liat. Truk-truk lalu-lalang mengangkut material ini di sepanjang jalan protokol yang menghubungkan Kabupaten Gowa dengan Kota Makassar. Bahan galian memang mampu memberikan pemasukan yang besar bagi kas Pemkab Gowa. Pos pajak ini mendominasi pendapatan hingga mencapai 65 persen dalam PAD tahun anggaran 2001 yang besarnya Rp. 3,11 miliar' ${ }^{1}$.

Potensi Wisata di Kabupaten Gowa bisa dikatakan cukup besar dan beragam dengan keindahan alam yang membentang dan kebesaran sejarah yang gemilang. Secara umum potensi wisata di Kabupaten Gowa dapat diklasifikasikan menjadi tiga kategori, yaitu: wisata alam dan wisata sejarah. Potensi wisata alam di Kabupaten Gowa cukup beragam di antaranya adalah air terjun Parangloe. Air Terjun Parang Loe, merupakan air terjun yang berada di Desa Belapunranga, Kecamatan Parangloe. Air terjun ini merupakan salah satu yang paling indah di

\footnotetext{
${ }^{1}$ Profil Kabupaten Gowa
} 
Sulawesi Selatan karena memiliki karakteristik air terjun yang bertingkat dengan susunan batu yang menarik. Tempat ini masih sangat alami dan masih jarang orang yang berkunjung. Untuk sampai dilokasi harus melewati jalan berbatu dan menuruni jalan setapak yang lumayan terjal. Air terjun ini berada tidak jauh dari jalan poros Makassar-Malino dan berjarak kurang lebih $25 \mathrm{~km}$ dari Kota Makassar.

Selain itu air terjun Parangloe, terdapat juga destinasi air terjun Tombolo Pao atau biasa juga disebut air terjun Bantimurung Gallang. Terletak di Desa Pao, Kecamatan Tombolo Pao atau sekitar kurang lebih $10 \mathrm{~km}$ dari Kota Malino. Air terjun ini sangat indah dan mudah untuk diakses. Air terjun di Kabuten Gowa cukup banyak jumlahnya, selain dua air terjun yang disebutkan sebelumnya, terdapat beberapa air terjun lainnya yang dapat dijadikan sebagai destinasi wisata, di antaranya, Air Terjun Takapala, Air Terjun Lembanna, Air Terjun Ketemu Jodoh, Permandian Lembah Biru, serta Danau Bendungan Bili-Bili. Destinasi wisata lainnya yang tidak kalah menarik adalah Hutan Wisata Malino (Hutan Pinus, Perkebunan Teh, serta Perkebunan Markisa yang terletak di daerah Tinggimoncong.

Adapun wisata sejarah dan wisata religi di Kabupaten Gowa tersebar di wilayah yang cukup terjangkau aksesnya dari kota Makassar seperti Masjid Katangka, Makam Sultan Hasanuddin, Makam Arung Palakka, Makam Syech Yusuf, Kompleks Istana Balla Lompoa, Benteng Somba Opu, Gowa Discovery Park. Keseluruhan destinasi tersebut terletak di Wilayah Kecamatan Somba Opu dan berbatasan langsung dengan Kota Makassar.

\section{PEMBAHASAN}

Berdasarkan analisis profil wilayah dan situasi masyarakat secara umum di Kabupaten Gowa, maka dirumuskan rancangan program kerja yang dilaksanakan selama KKN berlangsung adalah program pembinaan Al-Qur'an kepada masyarakat yang dikemas dalam bentuk Qur'anic Adventure. Kegiatan ini dimaksudkan agar masyarakat dapat lebih mendekatkan diri terhadap nilai-nilai Qur'aniyah serta sebagai pintu gerbang awal untuk keberlanjutan pembelajaran Islam secara intensif. Dalam implementasinya, pelaksanaan program kerja mengacu pada kebutuhan masyarakat pada lokasi objek KKN dan dilaksanakan sesuai dengan kebutuhan masyarakat setempat. Adapun rincian program Kerja KKN di Desa Majannang, Kec. Parigi, Kab. Gowa adalah sebagai berikut: 


\section{Halaqoh Qur'aniyah}

Halaqah Qur'aniyah adalah salah satu progam mahasiswa KKN angkatan IV tahun 2021 STIBA Makassar. Sasaran dari kegiatan ini adalah para santri Pondok Pesantren Binaan Wahdah Islamiyah di Kabupaten Gowa. Dalam halaqoh qur'aniyah yakni halaqoh tahsin dan halaqoh hafalan Qur'an. Pada halaqah tahsin, hal yang dipelajari dalam adalah tadarus, perbaikan bacaan, penjelasan tajwid, pemberian motivasi dalam mempelajari Al-Qur'an dan hal-hal yang berkaitan dengannya ${ }^{2}$.

Pada halaqoh hafalan Qur'an, kegiatan difokuskan dalam menambah jumlah setoran hafalan santri, sekaligus memperbaiki bacaan atau hafalan santri yang keliru ${ }^{3}$. Sejatinya tujuan dari program kerja ini yaitu, meningkatkan kualitas hafalan dan bacaan Al-Qur'an santri; dan meningkatkan kecintaan dan keistikamahan santri terhadap Al-Qur'an. Adapun langkah-langkah kegiatan adalah dengan membuat halaqoh, kemudian men-tahsin, tasmi' bacaan Al-Qur'an santri.

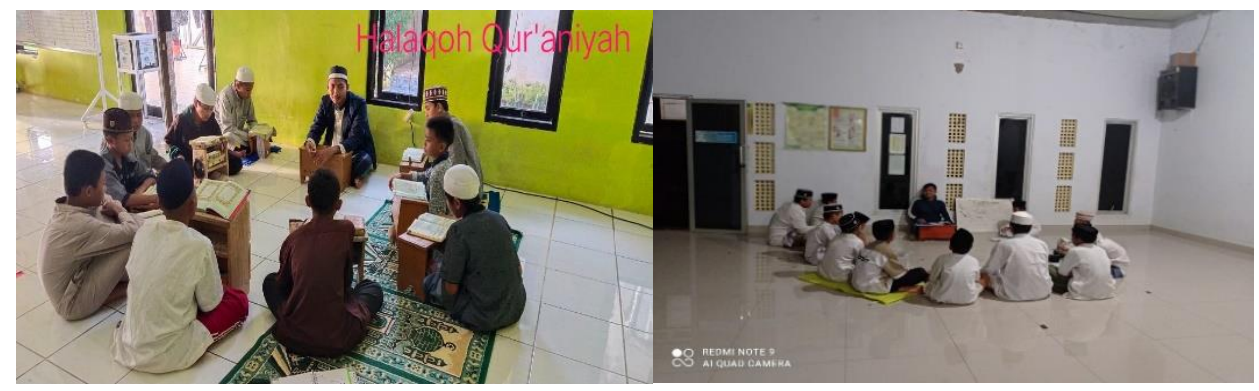

\section{Gambar 1. Halaqoh Qur'aniyah}

Program tersebut mendapatkan sambutan yang baik dari Asatidzah pembina Pondok Pesantren serta rasa antusiasme yang tinggi dari para peserta. Meskipun terdapat beberapa santri yang bacaanya kurang lancar sehingga haafalan yang ditargetkan tidak maksimal, tapi para mahasiswa berusaha semaksimal mungkin untuk memperbaiki atau mentahsin setiap kali ingin menghafal untuk mengurangi atau menghilangkan kesalahan saat menyetor hafalan

\section{Safari Dakwah dan Wakaf Qur'an}

Safari dakwah adalah salah satu progam mahasiswa KKN Angkatan IV tahun 2021 STIBA Makassar untuk melatih mahasiswa dan memberikan pemahaman kepada masyarakat. Sasaran dari kegiatan ini adalah masyarakat

\footnotetext{
${ }^{2}$ Putri, Sri Ujiana, and Aswar Aswar. "Implementasi Pendidikan Masyarakat Berbasis Masjid untuk Muslimah di Desa Mattoanging Kabupaten Maros." WAHATUL MUJTAMA': Jurnal Pengabdian Masyarakat 1.2 (2020): 129-141.

3 Tempo, Rachmat Bin Badani, and Khaerul Aqbar. "Ikhtiar Mahasiswa KKN STIBA Makassar dalam Pembentukan Akhlak Qur'ani Masyarakat Desa Balassuka Kabupaten Gowa." WAHATUL MUJTAMA': Jurnal Pengabdian Masyarakat 1.1 (2020): 90-115.
} 
Lembang Bu'ne Malakaji Kab. Gowa. Adapun tujuan dari program kerja ini yaitu, memberikan taklim dan pemahaman seputar ramadan untuk masyarakat, menambah wawasan masyarakat tentang bulan suci Ramadan, serta penyaluran wakaf Al-Qur'an dan iqro' untuk santri TK TPA Al-Muttaqin dan santri pesantren Markaz Tarbiyah Amal Jamiaatul Muslimin Kab. Gowa guna menambah kecintaan dan intensitas mereka dalam membaca Al-Qur'an di bulan Ramadan.

Kegiatan diawali dengan melakukan koordinasi kepada Ketua DPD WI Gowa, kemudian melakukan mempersiapkan materi yang akan diberikan kepada masyarakat. Tidak lupa tim membekali diri dengan penyediaan mushaf Al-Qur'an dan iqro'. Adapun Munawara dan Iskandar mengatakan bahwa program ini Wakaf Qur'an itu sejatinya dilatarbelakangi oleh kondisi warga muslim di suatu daerah yang mana menggunakan mushaf Al-Qur'an yang sudah tidak layak digunakan karena kondisinya sudah koyak, rusak, kotor, lusuh atau bernoda bintik-bintik, dan sebagainya ${ }^{4}$.

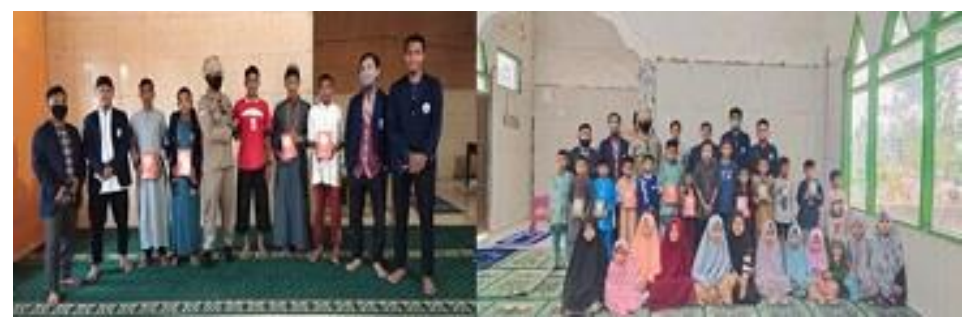

Gambar 2. Safari Dakwah dan Wakaf Qur'an

Kegiatan ini mendapatkan sambutan yang baik dari masyarakat setempat. Para santri anak-anak yang mendapatkan mushaf dan iqro' menunjukkan ekspresi Bahagia dan antusias. Keberhasilan program ini tidak terlepas dari sikap terbuka, ramah, dan santun dari masyarakat setempat, sehingga tim dapat menjalin hubungan baik dengan masyarakat. Meskipun terdapat kendala yakni kondisi jalan yang ditempuh sangat jauh dan kondisi cuaca yang kurang mendukung, namun tim dapat mentaktisi dengan persiapan yang matang dan timing keberangkatan yang tepat, sehingga kesulitan-kesulitan yang ada dapat diminimalisir.

\section{Pendidikan Al-Qur'an Muslimah (DIROSA)}

DIROSA merupakan salah satu proker mahasiswi KKN Ang. IV Kab. Gowa, yang mengajarkan metode DIROSA khusus kepada remaja maupun orang dewasa dengan memakai buku DIROSA. Kegiatan ini sangat bermanfaat untuk memudahkan remaja dan orang dewasa belajar membaca Al-Qur'an. Tujuan dari

${ }^{4}$ Munawara, Munawara, and Iskandar Iskandar. "Implementasi Pengabdian Masyarakat melalui Pelaksanaan Dirasah Islamiyah di Desa Tukamasea Kabupaten Maros." WAHATUL MUJTAMA': Jurnal Pengabdian Masyarakat 1.2 (2020): 174-184. 
program ini adalah memperbaiki bacaan Al-Qur'an muslimah sesuai kaidah ilmu tajwid dan agar warga dapat dikondisikan untuk semakin dekat dengan Al-Qur'an. Berdasarkan hasil kegiatan PkM yang dilakukan oleh Hendra dan Nurhidayah berkenaan dengan pengajaran Dirosa, menunjukkan bahwa sebagian besar peserta sebelum mengikuti program Dirosa belum lancar membaca Al-Qur'an, tidak paham kaidah tajwid dan bahkan di antara peserta ada yang buta aksara AlQur'an, dan setelah mengikuti program Dirosa peserta menjadi mahir membaca AlQur'an sesuai kaidah tajwid'.

Kegiatan ini dilaksanakan sebanyak dua atau tiga kali sepekan (disesuaikan dengan jadwal mengajar tiap mahasiswi di kecamatan masing-masing), baik secara online via Zoom ataupun offline sesuai dengan kondisi daerah masing-masing. Meskipun format awal kegiatan dilaksanakan secara full online, akan tetapi bagi daerah yang sudah kondisif dari pandemi atau dari kalangan keluarga bisa unjuk mengajar secara offline. Selama KKN IV berlangsung, mahasiswi berhasil mengumpulkan 54 orang selama 1 bulan penuh yang telah dibagi menjadi 9 halaqah, beberapa kelompok halaqoh diambil dari halaqoh yang diamanahkan oleh MWD (Muslimah Wahdah) dan beberapa lainnya dari hasil pembentukan mandiri mahasiswa KKN yang melakukan sosialisasi kepada muslimah setempat.



Gambar 3. Pembelajaran Al-Qur'an Muslimah Dewasa (Online dan Offline)

Antusias masyarakat dalam mengikuti kegiatan ini terlihat sangat baik terlebih karena kegiatan dirosa ini mendapatkan dukungan penuh dari Muslimah Wahdah Kabupaten Gowa. Adapun tantangan dari pelaksanaan kegiatan ini adalah kesibukan masyarakat, sehingga membutuhkan pengaturan yang baik dalam mencari waktu yang tepat untuk belajar. Oleh karena itu, masyarakat senantiasa diberikan penguatan tentang perlunya menuntut ilmu untuk mencapai peningkatan derajat di sisi Allah Ta'ala. Selain itu, perlunya memberikan rasa optimis kepada mereka bahwasanya mereka bisa membaca Al-Qur'an.

${ }^{5}$ Wijaya, Hendra. "Pembelajaran Metode Dirosa di Desa Majannang Kabupaten Gowa." WAHATUL MUJTAMA': Jurnal Pengabdian Masyarakat 1.1 (2020): 67-74. 


\section{Pembinaan Taman Pendidikan Al-Qur'an (TPA)}

Pembinaan Taman Pendidikan Al-Qur'an (TPA) merupakan salah satu proker mahasiswi KKN STIBA Makassar untuk seluruh anak-anak TK/TPA binaan para Muslimah Wahdah. Pembinaan Taman Pendidikan Al-Qur'an (TPA) merupakan ajang pengabdian untuk menambah pengetahuan anak-anak terutama dalam hal Al-Qur'an dan pengamalan keagamaan. TPA atau kepanjangan dari Taman Pendidikan Al-Quran memang diperankan oleh anak-anak, karena pada usia dini anak-anak masih dalam tahap perkembangan kognitif ${ }^{6}$.

Metode yang digunakan berbeda-beda pada setiap TK/TPA yang menjadi binaan Muslimah Wahdah Cabang (MWC), mulai dari yang menggunakan Metode Tilawati juga ada yang menggunakan metode biasa yang seperti pada umumnya. Pembinaan Taman Pendidikan Al-Qur'an (TPA) diharapkan mampu menumbuhkan karakter sejak dini agar mampu memahami dan mengamalkan AlQur'an serta memiliki akhlak karimah para anak-anak santri/santriwati.

Tujuan kegiatan ini adalah membantu santri/santriwati menumbuhkan rasa kagum dan cinta terhadap Al-Qur'an serta memperbaiki huruf sesuai tajwidnya. Kegiatan dilaksanakan setiap hari Senin sampai Jumat jam 16.00 - 17.15 di tiga lokasi berbeda, yaitu TK/TPA binaan Muslimah Wahdah Cabang Pallangga, TK/TPA binaan Muslimah Wahdah Cabang Somba Opu, dan TK/TPA binaan Muslimah Wahdah Cabang Bajeng dengan masing-masing rincian peserta adalah Pallangga 120 orang, Somba Opu 30 Orang, dan Bajeng 50 Orang.

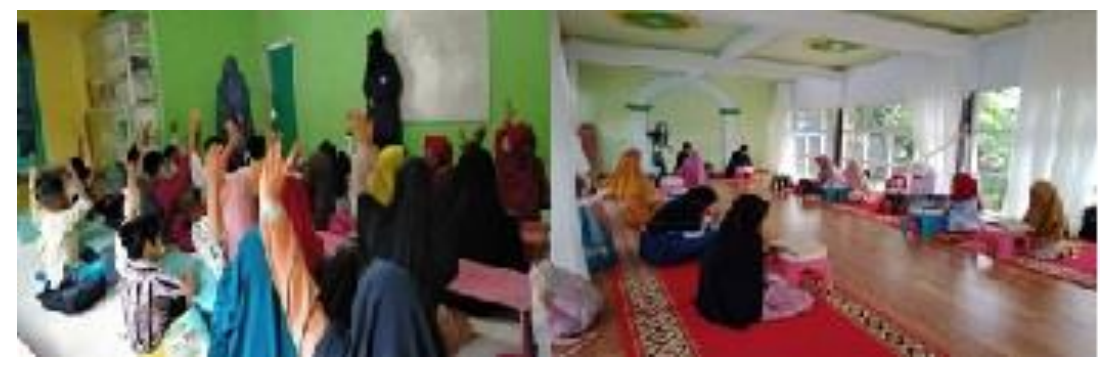

Gambar 4. Pembinaan Taman Pendidikan Al-Qur’an

Kegiatan pembinaan TK/TPA setiap harinya senantiasa diawali dengan doa kemudian pengontrolan kehadiran. Setelah itu dilakukan murajaah doa harian dan hafalan Al-Qur'an yang kemudian dilanjutkan dengan membaca bacaan tilawati dan pemeriksaan berbahasa Arab dari buku tilawati tersebut. Di akhir sesi pertemuan, para santri/santriwati akan diminta untuk menambah hafalan baik doa

${ }^{6}$ Muin, Istikhariyah, and M. Amirullah. "Gerakan Literasi Islamiyah melalui Program Dakwah dan Tarbiyah di Desa Mangeloreng Kabupaten Maros." WAHATUL MUJTAMA': Jurnal Pengabdian Masyarakat 1.2 (2020): 200-208. 
harian maupun hafalan surah pendek dan disetorkan sebelum pulang. Antusiasme santri/santriwati serta respom positif dari pembina TK/TPA menjadi faktor penting dalam mendukung serta mensukseskan kegiatan pembinaan TK/TPA oleh mahasiswa KKN STIBA Makassar.

\section{Tahfiz Weekend Muslimah}

Tahfiz Weekend Muslimah merupakan program yang menghafal Al-Qur'an khusus Muslimah di akhir pekan yaitu setiap sabtu, yang merupakan salah satu proker mahasiswa KKN STIBA Makassar. Tujuan dari kegiatan ini adalah mengajarkan anak-anak untuk mengenal Islam melalui Al-Qur'an, menumbuhkan kesenangan dalam membaca Al-Qur'an, menambah hafalan, dan murajaah hafalan, serta mampu menyetorkan hafalan minimal 1 halaman selama waktu penyetoran hafalan berjalan. Senada dengannya, Rahmat dan Khaerul mengatakan bahwa program Tahfiz pada dasarnya berarah tujuan dalam memperbaiki bacaan atau hafalan yang keliru, dan tentunya dapat menambah jumlah setoran hafalan seseorang ${ }^{7}$.

Pelaksanaan kegiatan Tahfiz Weekend Muslimah dilaksanakan setiap sekali dalam sepekan dengan berlokasi di tempat yang disesuaikan dengan daerah masingmasing mahasiswi KKN STIBA Makassar. Peserta Tahfiz Weekend Muslimah didominasi oleh para pelajar dan anak-anak karena dilaksanakan setiap akhir pekan sehingga praktis tidak mengganggu aktivitas belajar mereka di sekolah sehari-hari. Faktor Pendukung dari kegiatan ini adalah dukungan dari masyarakat dan orang tua yang sangat kooperatif dalam mendukung anak-anak mereka agar dapat menjadi seorang penghafal Al-Qur'an. Kegiatan ini juga dimanfaatkan oleh mahasiswa KKN STIBA Makassar sebagai wadah untuk bersilaturahim dengan masyarakat.

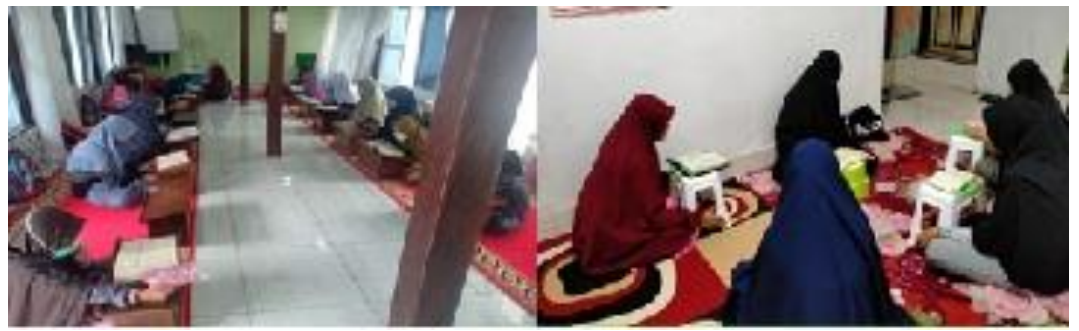

Gambar 5. Tahfiz Weekend Muslimah

7 Tempo, Rachmat Bin Badani, and Khaerul Aqbar. "Ikhtiar Mahasiswa KKN STIBA Makassar dalam Pembentukan Akhlak Qur'ani Masyarakat Desa Balassuka Kabupaten Gowa." WAHATUL MUJTAMA': Jurnal Pengabdian Masyarakat 1.1 (2020): 90-115. 


\section{KESIMPULAN}

Berdasarkan uraian di atas dapat disimpulkan bahwa secara umum, program-program yang telah diseminarkan dapat berjalan dengan baik. Berdasarkan pengalaman dan kondisi lapangan diperoleh selama kegiatan dapat disimpulkan bahwa program Kuliah Kerja Nyata telah terencana dengan baik dan dapat berjalan dengan lancar, meskipun ada kegiatan yang tidak terlaksana sesuai dengan waktu yang telah direncanakan. Akan tetapi berubah jadwal karena faktor cuaca dan kegiatan yang tidak terencana dari sasaran. Program Kuliah Kerja Nyata dapat meningkatkan ilmu dan pengetahuan masyarakat serta dapat menggugah masyarakat terutama dalam bidang spiritual.

Adapun manfaat yang diperoleh mahasiswa adalah terbentuknya pribadi mahasiswa menjadi lebih dewasa dalam menyikapi permasalahan yang ada dan dapat memahami bagaimana cara bermasyarakat. Selain itu, dapat membentuk kepribadian yang mandiri dan bertanggung jawab terhadap tugas dan fungsinya serta membentuk jiwa kepemimpinan. Selain itu, mahasiswa mendapatkan pengalaman dan ilmu kemasyarakatan yang tidak didapatkan dibangku kuliah dan masyarakat yang mampu menyerap ilmu yang dimiliki mahasiswa dalam meningkatkan wawasan mereka untuk diterapkan dalam kehidupan sehari-hari.

Pengalaman membuat kegiatan atau acara-acara yang tentunya diharapkan dapat bermanfaat bagi mahasiswa ke depan. Tidak kalah penting adalah program KKN bagi mahasiswa memupuk rasa percaya diri dalam menghadapi warga masyarakat, serta dapat berpartisipasi dalam kehidupan masyarakat yang beradaptasi dengan kehidupan bermasyarakat. Selain itu, mahasiswa dapat memahami kultur dan karakter serta adat istiadat. Dengan adanya Kuliah Kerja Nyata mahasiswa dapat melihat bagaimana mengaplikasikan ilmu yang didapat di bangku kuliah.

\section{DAFTAR PUSTAKA}

Profil Kabupaten Gowa

Putri, Sri Ujiana, and Aswar Aswar. "Implementasi Pendidikan Masyarakat Berbasis Masjid untuk Muslimah di Desa Mattoanging Kabupaten Maros." WAHATUL MUJTAMA': Jurnal Pengabdian Masyarakat 1.2 (2020): 129-141.

Tempo, Rachmat Bin Badani, and Khaerul Aqbar. "Ikhtiar Mahasiswa KKN STIBA Makassar dalam Pembentukan Akhlak Qur'ani Masyarakat Desa Balassuka Kabupaten Gowa." WAHATUL MUJTAMA': Jurnal Pengabdian Masyarakat 1.1 (2020): 90-115. 
- Jurnal — WAHATUL MUJTAMA': Jurnal Pengabdian Masyarakat

WAHATUL Vol. 2, No. 1 (2021): Hal. 58-69

MUJTAMA'

JURNAL PENGABDIAN

Website: https://journal.stiba.ac.id

ISSN: 2723-6013 (Online)

Muin, Istikhariyah, and M. Amirullah. "Gerakan Literasi Islamiyah melalui Program Dakwah dan Tarbiyah di Desa Mangeloreng Kabupaten Maros." WAHATUL MUJTAMA': Jurnal Pengabdian Masyarakat 1.2 (2020): 200208.

Munawara, Munawara, and Iskandar Iskandar. "Implementasi Pengabdian

Masyarakat melalui Pelaksanaan Dirasah Islamiyah di Desa Tukamasea

Kabupaten Maros." WAHATUL MUJTAMA': Jurnal Pengabdian Masyarakat 1.2 (2020): 174-184.

Wijaya, Hendra. "Pembelajaran Metode Dirosa di Desa Majannang Kabupaten Gowa." WAHATUL MUJTAMA': Jurnal Pengabdian Masyarakat 1.1 (2020): 67-74. 